\title{
Evaluation of Durability to Laundering of Triclosan and Chitosan on a Textile Substrate
}

\author{
Anupama Sargur Ranganath ${ }^{1}$ and Ajoy K. Sarkar ${ }^{2}$ \\ ${ }^{1}$ Department of Design and Merchandising, Colorado State University, Fort Collins, CO 80523, USA \\ ${ }^{2}$ Textile Development and Marketing, Fashion Institute of Technology, State University of New York, NY 10001-5992, USA
}

Correspondence should be addressed to Ajoy K. Sarkar; ajoy_sarkar@exchange.fitnyc.edu

Received 11 January 2014; Revised 19 June 2014; Accepted 22 June 2014; Published 2 July 2014

Academic Editor: Sambandam Anandan

Copyright ( 2014 A. S. Ranganath and A. K. Sarkar. This is an open access article distributed under the Creative Commons Attribution License, which permits unrestricted use, distribution, and reproduction in any medium, provided the original work is properly cited.

\begin{abstract}
In a hospital environment, textile substrates have been implicated as a vector in the transmission of disease. To mitigate the harmful spread of disease via textile substrates, an effective measure is treatment of textiles with antimicrobial agents. The current investigation compares one of the most widely used chemically synthesized antimicrobial agents, triclosan with chitosan, a naturally occurring antimicrobial agent. For the study, samples of a common polyester/cotton textile used in hospital settings were treated with triclosan and chitosan based antimicrobial agents. Following treatment, the samples were analyzed for their effectiveness against Staphylococcus aureus and Escherichia coli using standard AATCC Test Methods. The efficacy of the treatment to laundering was then evaluated by subjecting the treated samples to 50 washings and repeating the tests against the challenge microorganisms. Data obtained were statistically analyzed at a 95\% confidence interval. Results showed that before laundering both triclosan and chitosan treated samples were extremely effective as antimicrobial agents. After laundering, chitosan was less effective against E.coli but maintained efficacy against $S$. aureus. The effectiveness of triclosan was not adversely affected after the laundering treatments.
\end{abstract}

\section{Introduction}

The Centers for Disease Control and Prevention, USA, estimate that approximately 1.7 million healthcare associated infections (HAIs) and 98,987 associated deaths occur each year on account of infection-causing bacteria. Hence, the control of infections has been identified as the most important target by the United States Department of Health and Human Services [1]. Textile substrates have been implicated as one of the vectors of transmission of infections. Fortuitously, the use of antimicrobial textiles is an effective deterrent against the spread of infection-causing bacteria [2].

Triclosan, a chlorinated phenolic compound, is a derivative of a diphenyl ether compound. Triclosan is most widely used in various medical and consumer care products. Triclosan belongs to leaching or controlled release category of antimicrobial agents [2,3]. The mechanism of action of triclosan on a textile substrate is illustrated in Figure 1. The figure depicts a treated fiber containing a reservoir of antimicrobial agent. When the chemical agent ions are released outside the fiber they destroy microbes present in the vicinity. Triclosan inhibits the growth of microbes by using an electrochemical mode of action to penetrate and disrupt the cell wall of microbes $[2,4]$. It is probable that, with eventual usage and repetitive laundering of the treated material, the reservoir in the fiber will get depleted and lose its antimicrobial efficacy [5]. As well, via launderings the ions may enter the water stream. Triclosan has been reported to cause environmental problems due to its nonbiodegradability. Other studies have reported increased resistance to triclosan by certain strains of $S$. aureus and other bacteria. The U.S. Food and Drug Administration is currently engaged in an ongoing scientific and regulatory review of triclosan [6].

Chitin, a poly( $\beta-(1-4)-\mathrm{N}$-acetyl-D-glucosamine), is a natural polysaccharide. Chitin is synthesized by many living organisms. It is the most abundantly found polymer second only to cellulose. When chitin is acetylated to at least about $50 \%$, it is called chitosan [7]. Chitosan belongs to the category of nonleaching or the bound type antimicrobial agents, wherein the antimicrobial agent is fixed to the fiber surface via 


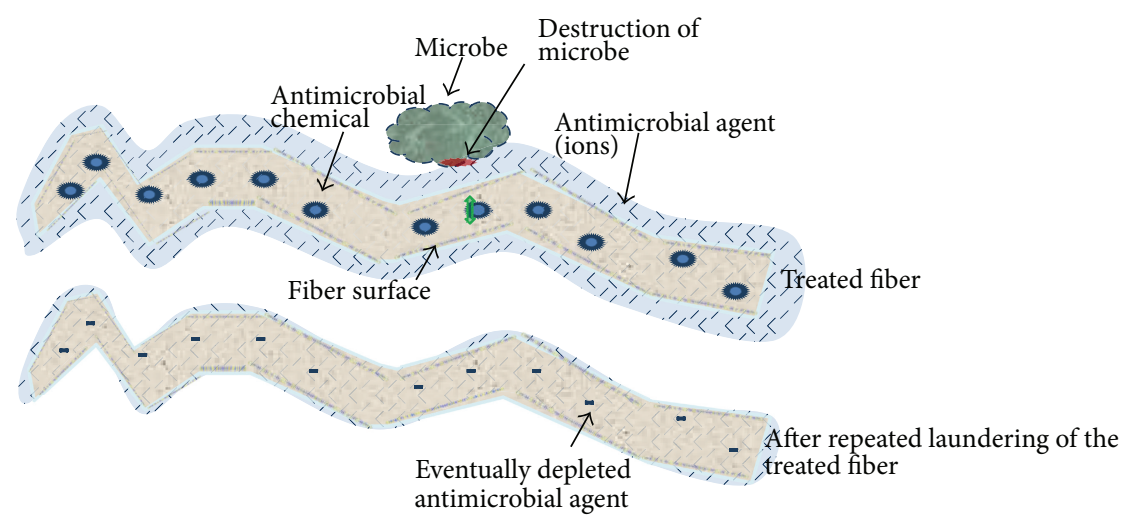

Figure 1: Mechanism of action of triclosan.

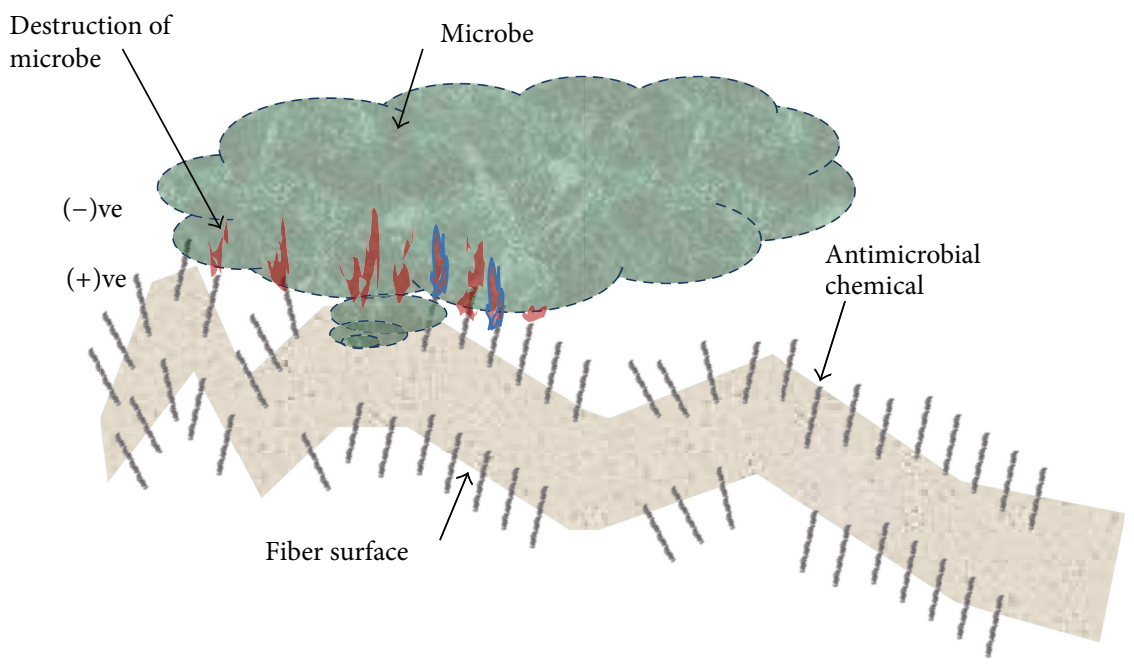

FIgURE 2: Mechanism of action of chitosan.

covalent bonds and is able to destroy the microbes that come in contact with the fiber [2]. The mechanism of action of chitosan on a textile substrate is shown in Figure 2. Mechanism studies suggest that the positively charged chitosan interacts with negatively charged residues at the cell wall of fungi or bacteria. The interaction changes cell permeability and causes the leakage of intracellular substances $[8,9]$. Other studies suggest that the formation of the polymeric substance around the bacterial cell prevents the nutrients from entering the cell [10].

Based on a literature review of antimicrobial textiles, it was found that a majority of the research conducted to date has focused on synthesizing and evaluating uniquely distinct antimicrobial agents on different textile substrates with the purpose of proving their effectiveness against microbes. Very few studies have concentrated on comparing the durability to laundering and antimicrobial efficacy of different agents on a specific substrate against target challenge microorganisms. Therefore, the endeavor of the present research was to evaluate the durability to laundering of two such agents, triclosan and chitosan. Secondly, as mentioned before, there are rising concerns with regard to triclosan, a chemically synthesized agent. The study would consequently also shed light on whether chitosan, a naturally derived antimicrobial agent, could serve as a potential replacement for synthetic antimicrobial agents.

\section{Materials and Methods}

2.1. Materials. The antimicrobial agent based on triclosan was a halogenated phenol with the chemical constitution 5-chloro-2-(2,4-dichlorophenoxy) phenol. A 6\% chitosan based formulation was the other antimicrobial agent. The plain weave fabric treated with the two antimicrobial agents had the following characteristics: fiber content: $65 \%$ polyester $/ 35 \%$ cotton; weight: $154 \mathrm{~g} / \mathrm{m}^{2}$ (ASTM D3776); fabric count: 158; and thickness: 0.017 inches (ASTM D1777-96). The treated substrates were challenged against Staphylococcus aureus (ATCC 6538, PML Microbiologicals, Inc.), Gram positive bacteria, and Escherichia coli (ATCC 8739, PML Microbiologicals, Inc.), Gram negative bacteria.

2.2. Methods. The purpose of the study was to compare the antimicrobial efficacy of triclosan and chitosan when applied to a substrate using manufacturers' recommended 
concentration and treatment protocols. Adhering to the recommendations ensured optimum performance of the two agents. Hence, the treatment methods for triclosan and chitosan are different as enumerated below.

\subsubsection{Triclosan Treatment Method. The substrate was washed} to remove dust and other impurities. Exhaust procedure was adopted to treat the substrate with triclosan. The concentration of triclosan used was $4 \%$ on weight of fabric (owf) with a material to liquor ratio (MLR) of 1:50. As per the MLR calculations, required amount of water was measured in a treatment bath and heated to $50^{\circ} \mathrm{C}$. Triclosan was added to the bath and $\mathrm{pH}$ was maintained between 4 and 6 . The substrate was then added to the bath and temperature increased to $120^{\circ} \mathrm{C}$. Treatment was continued at this temperature for 60 minutes. Finally fabrics were rinsed and air-dried.

2.2.2. Chitosan Treatment Method. The substrate was washed to remove dust and other impurities. Treatment of the substrate with a chitosan based antimicrobial agent was done by the pad-cure method. In this method, the chitosan based antimicrobial was diluted with 20 parts of water for 1 part of chitosan. The diluted solution was considered as the stock solution. The optimum concentration for the treatment was $2 \%$ on weight of the stock solution. The bath was prepared with the required amount of water as per MLR of $1: 20$ and required amount of stock solution of chitosan. The $\mathrm{pH}$ of the bath was maintained between 4.5 and 5.5 for the entire duration of treatment. To increase the affinity and durability of chitosan for the substrate, $0.4 \%$ of a binder was also added to the treatment bath. The substrate was then immersed in the bath for 5 minutes at room temperature followed by one nip through the squeezing rollers to remove any excess liquor. The substrate was then cured at $149^{\circ} \mathrm{C}$ in the curing chamber for 5 minutes.

2.2.3. Laundering Procedure. The treated samples were laundered using AATCC Test Method 61, 3A with modifications to mimic harsher industrial laundry conditions. Launderings were carried out using MLR of $1: 10$ with $0.5 \%$ on weight of fabric of AATCC detergent and 100 steel balls at a temperature of $90^{\circ} \mathrm{C}$ for 30 minutes. Washing cycle was followed by rinsing in plain water at $40^{\circ} \mathrm{C}$ for 10 minutes followed by tumble drying. Since a single wash-dry cycle simulated 5 regular wash cycles, the laundering procedure was repeated 10 times to obtain samples after 50 wash cycles.

2.2.4. Evaluation Methods. Treated and washed samples were challenged with strains of $S$. aureus and E. coli. The antibacterial activity was evaluated using AATCC Test Method 147: Antibacterial Assessment of Textile Materials: Parallel Streak Method and AATCC Test Method 100: Assessment of Antibacterial Finishes on Textile Materials.

For AATCC Test Method 147, specimen sizes of $25 \times$ $50 \mathrm{~mm}$ were used. A loop full of the respective culture was transferred to the surface of a sterile agar plate by making five streaks approximately $60 \mathrm{~mm}$ in length, spaced $10 \mathrm{~mm}$ apart, covering the central area of the Petri dish. The specimen was then gently pressed transversely across the five streaks to ensure intimate contact with the agar surface. The plates were incubated at $37^{\circ} \mathrm{C}$ for $18-24$ hours and were examined for interruption of growth along the streaks of inoculum beneath the specimen and for a clear zone of inhibition beyond its edge. The average width of a zone of inhibition (ZOI) along a streak on either side of the test specimen was calculated using

$$
W=\frac{(T-D)}{2},
$$

where $W$ is the average width of clear zone of inhibition in $\mathrm{mm}, T$ is the total diameter of test specimen and clear zone in $\mathrm{mm}$, and $D$ is the diameter of the test specimen in $\mathrm{mm}$.

For AATCC Test Method 100, three discs of treated and untreated samples measuring $48 \mathrm{~mm}$ were inoculated with $1 \mathrm{~mL}$ of inoculum $\left(1-2 \times 10^{5}\right.$ organisms $)$ in two separate $100 \mathrm{~mL}$ jars. The jars were incubated for 24 hours at $37^{\circ} \mathrm{C}$. The samples were then neutralized with $100 \mathrm{~mL}$ of Tween 80 solution (Sigma-Aldrich) and were vigorously shaken for 1 minute. The solution was then eluted and plated with appropriate dilution in order to obtain countable colonies. The percent reduction of bacteria was calculated using

$$
R=\frac{(B-A) * 100}{B},
$$

where $R$ is the percent reduction of bacteria, $A$ is the number of bacteria recovered from the inoculated treated test samples in the jar incubated over the desired contact period, and $B$ is the number of bacteria recovered from the inoculated untreated test samples in the jar incubated over the desired contact period.

2.2.5. Statistical Analysis. The antimicrobial properties and durability to laundering of the antimicrobial treated fabrics were compared using Statistical Analysis System (SAS version 9.2, Cary, NC). The null hypothesis was that there were no statistically significant differences between triclosan and chitosan on a textile substrate. A three-factor design was used to structure the experiment, wherein the independent factors were antimicrobial agents, wash cycles, and bacteria. The treatment procedure, laundering, and antimicrobial testing of samples were replicated three times. The statistical evaluation was done using analysis of variance (ANOVA) at a $95 \%$ confidence level.

\section{Results and Discussion}

The mean zone of inhibition (ZOI, $\mathrm{mm}$ ) as calculated using AATCC Test Method 147 for the polyester/cotton treated with triclosan and chitosan is shown in Table 1. Actual illustrative photographs against $E$. coli are displayed in Figures 3 and 4.

For purposes of this study, a mean ZOI of $2 \mathrm{~mm}$ was considered an indication of effective antimicrobial activity. Triclosan was found to possess excellent antimicrobial action against both S. aureus and E. coli (Table 1 and Figure 3). The mean ZOI against $S$. aureus before laundering the treated substrate was $22.2 \mathrm{~mm}$ and after 50 laundry cycles there was a slight decrease to $21.1 \mathrm{~mm}$ conclusively proving 


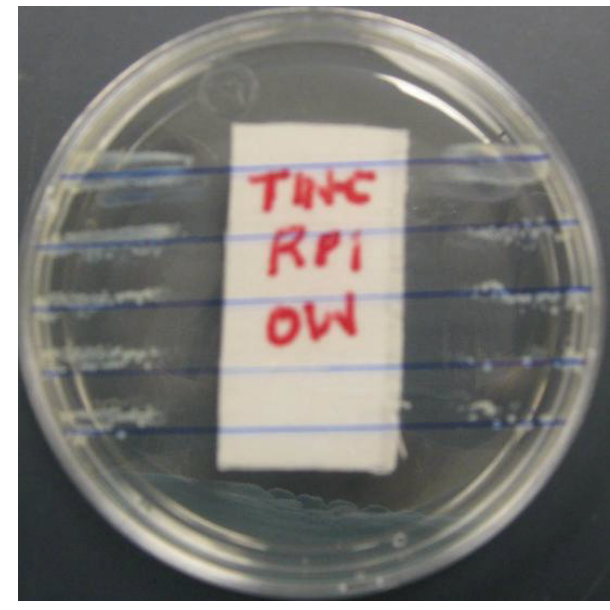

(a)

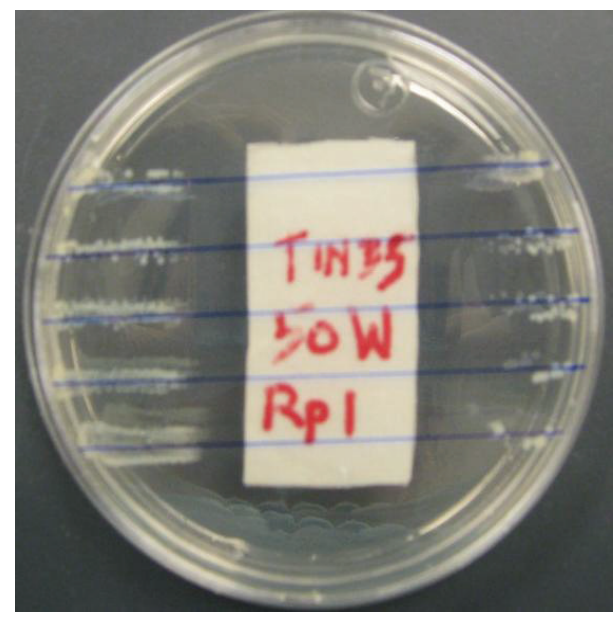

(b)

FIGURE 3: Zone of inhibition of triclosan treated polyester/cotton blend against E. coli: after treatment (a) and after 50 laundry cycles (b).

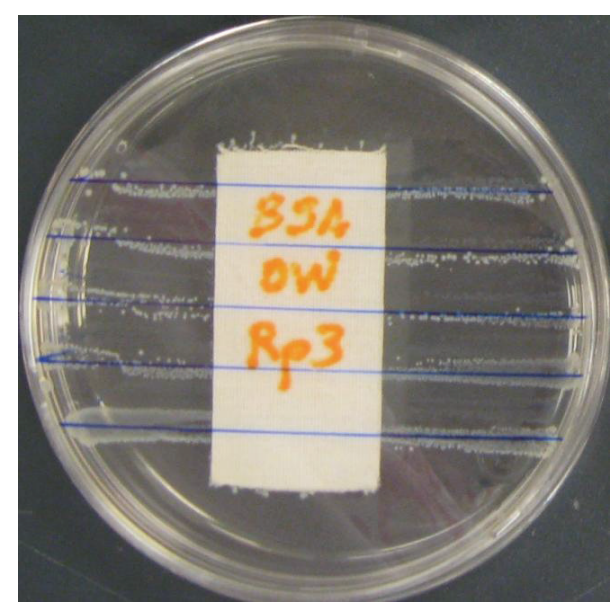

(a)

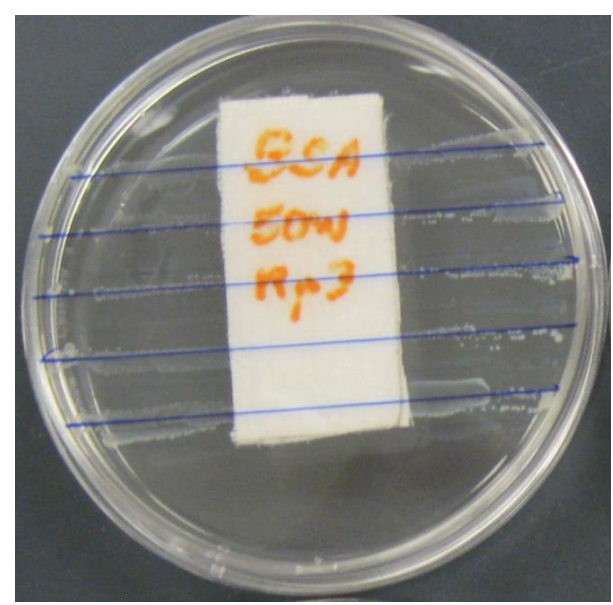

(b)

FIGURE 4: Zone of inhibition of chitosan treated polyester/cotton blend against E. coli: after treatment (a) and after 50 laundry cycles (b).

TABLE 1: Mean zone of inhibition ( $\mathrm{mm}$ ) for treated polyester/cotton substrate against $S$. aureus and E. coli after treatment (0 laundry cycles) and after 50 laundry cycles.

\begin{tabular}{|c|c|c|c|c|}
\hline \multirow{3}{*}{ Antimicrobial agent } & \multicolumn{2}{|c|}{ S. aureus ZOI (mm) } & \multicolumn{2}{|c|}{ E. coli ZOI (mm) } \\
\hline & \multicolumn{4}{|c|}{ Laundry cycles } \\
\hline & 0 & 50 & 0 & 50 \\
\hline Triclosan & 22.2 & 21.1 & 8.5 & 7.8 \\
\hline Chitosan & 0.0 & 0.0 & 0.0 & 0.0 \\
\hline
\end{tabular}

the durability to laundering of the samples treated with triclosan. The values against $E$. coli were $8.5 \mathrm{~mm}$ before laundering and $7.8 \mathrm{~mm}$ after 50 laundry cycles again clearly underscoring the excellent and durable antimicrobial properties of triclosan based antimicrobials. The mean ZOI for chitosan treated substrates was $0 \mathrm{~mm}$ against both types of bacteria (Table 1 and Figure 4). This result is logical because AATCC Test Method 147 works best with leaching type of
TABLE 2: Percentage reduction in bacteria of treated polyester/cotton substrate against $S$. aureus and E. coli after treatment (0 laundry cycles) and after 50 laundry cycles.

\begin{tabular}{|c|c|c|c|c|}
\hline \multirow{3}{*}{ Antimicrobial agen } & \multicolumn{4}{|c|}{ S. aureus (\% reduction) } \\
\hline & \multicolumn{4}{|c|}{ Laundry cycles } \\
\hline & 0 & 50 & 0 & 50 \\
\hline Triclosan & 100.0 & 100.0 & 100.0 & 100.0 \\
\hline Chitosan & 100.0 & 92.0 & 99.6 & 51.0 \\
\hline
\end{tabular}

antimicrobials and as explained previously chitosan belongs to the bound or nonleaching type of antimicrobials. The nonleaching characteristic of chitosan was further emphasized by the absence of bacteria on the underside of the fabrics.

Table 2 reports the results obtained using AATCC Test Method 100. The data for triclosan are consistent with the results obtained using AATCC Test Method 147. Triclosan was extremely effective against both types of bacteria and 
TABLE 3: Statistical comparison ( $P$ values) of polyester/cotton substrate against $S$. aureus and E. coli after treatment (0 laundry cycles) and after 50 laundry cycles.

\begin{tabular}{lcccc}
\hline & \multicolumn{3}{c}{ S. aureus } & \multicolumn{2}{c}{ E. coli } \\
Antimicrobial agent & \multicolumn{4}{c}{ Laundry cycles } \\
& 0 & 50 & 0 & 50 \\
\hline $\begin{array}{l}\text { Triclosan (agent 1) } \\
\text { Chitosan (agent 2) }\end{array}$ & 1 & 0.29 & 0.35 & $<0.0001$ \\
\hline
\end{tabular}

the efficacy did not diminish after 50 launderings. Antimicrobial activity of chitosan against $S$. aureus and E. coli and after treatment was excellent as well with $100 \%$ and $99.6 \%$ reduction of bacteria, respectively. After 50 laundering cycles, the activity against $S$. aureus remained high and only slightly decreased to $92 \%$. However, the efficacy of chitosan against $E$. coli reduced significantly to $51 \%$ after 50 launderings. A probable explanation is that the stronger outer cell wall of Gram negative bacteria such as E. coli restricts the antimicrobial molecules from penetrating and killing the bacteria efficiently.

Statistical analysis (Table 3) showed that the efficacies of unlaundered samples ("0" wash cycles) of substrates treated with triclosan and chitosan against $E$. coli were not statistically different from each other $(P$ value $=0.35)$. Similarly, against $S$. aureus both the agents exhibited $100 \%$ reduction of bacteria and therefore $P=1$. After 50 launderings, the performance of chitosan against $E$. coli was reduced to $51 \%$ which was statistically significant compared to triclosan which exhibited $100 \%$ reduction $(P$ value $<0.0001)$. Against $S$. aureus, chitosan at $92 \%$ bacterial reduction had less absolute efficacy than triclosan $(100 \%)$ but this difference was not statistically significant $(P$ value $=0.29)$.

\section{Conclusions}

The results of this study show that treatment of polyester/ cotton substrate with the naturally occurring antimicrobial agent, chitosan, imparted antimicrobial activity against both $S$. aureus and E. coli. The treatment was very durable to laundering against the Gram positive bacteria but less durable against the Gram negative bacteria. The research thus suggests that chitosan based natural antimicrobial agent has the potential to be a viable alternative to chemically synthesized antimicrobial agents such as triclosan especially in light of the reported adverse impact of widespread use of chemically synthesized antimicrobial agents.

\section{Conflict of Interests}

The authors declare that there is no conflict of interests regarding the publication of this paper.

\section{References}

[1] Centers for Disease Control and Prevention, USA, 2014, http:// www.cdc.gov/ncidod/dhqp/pdf/StateHAI_PlanningTemplate .pdf.
[2] Y. Gao and R. Cranston, "Recent advances in antimicrobial treatments of textiles," Textile Research Journal, vol. 78, no. 1, pp. 60-72, 2008.

[3] B. Simoncic and B. Tomsic, "Structures of novel antimicrobial agents for textiles: a review," Textile Research Journal, vol. 80, no. 16, pp. 1721-1737, 2010.

[4] R. Purwar and M. Joshi, "Recent developments in antimicrobial finishing of textiles-a review," AATCC Review, vol. 4, no. 3, pp. 22-26, 2004.

[5] M. Orhan, D. Kut, and C. Gunesoglu, "Use of triclosan as antibacterial agent in textiles," Indian Journal of Fibre and Textile Research, vol. 32, no. 1, pp. 114-118, 2007.

[6] U.S. Food and Drug Administration, 2014, http://www.fda.gov/ forconsumers/consumerupdates/ucm205999.htm.

[7] M. Rinaudo, "Chitin and chitosan: properties and applications," Progress in Polymer Science, vol. 31, no. 7, pp. 603-632, 2006.

[8] S.-H. Lim and S. M. Hudson, "Review of chitosan and its derivatives as antimicrobial agents and their uses as textile chemicals," Journal of Macromolecular Science, vol. 43, no. 2, pp. 223-269, 2003.

[9] D. H. Young, H. Kohle, and H. Kauss, "Effect of chitosan on membrane permeability of suspension-cultured glycine max and Phaseolus vulgaris cells," Plant Physiology, vol. 70, no. 5, pp. 1449-1454, 1982.

[10] I. M. Helander, E.-L. Nurmiaho-Lassila, R. Ahvenainen, J. Rhoades, and S. Roller, "Chitosan disrupts the barrier properties of the outer membrane of Gram-negative bacteria," International Journal of Food Microbiology, vol. 71, no. 2-3, pp. 235-244, 2001. 

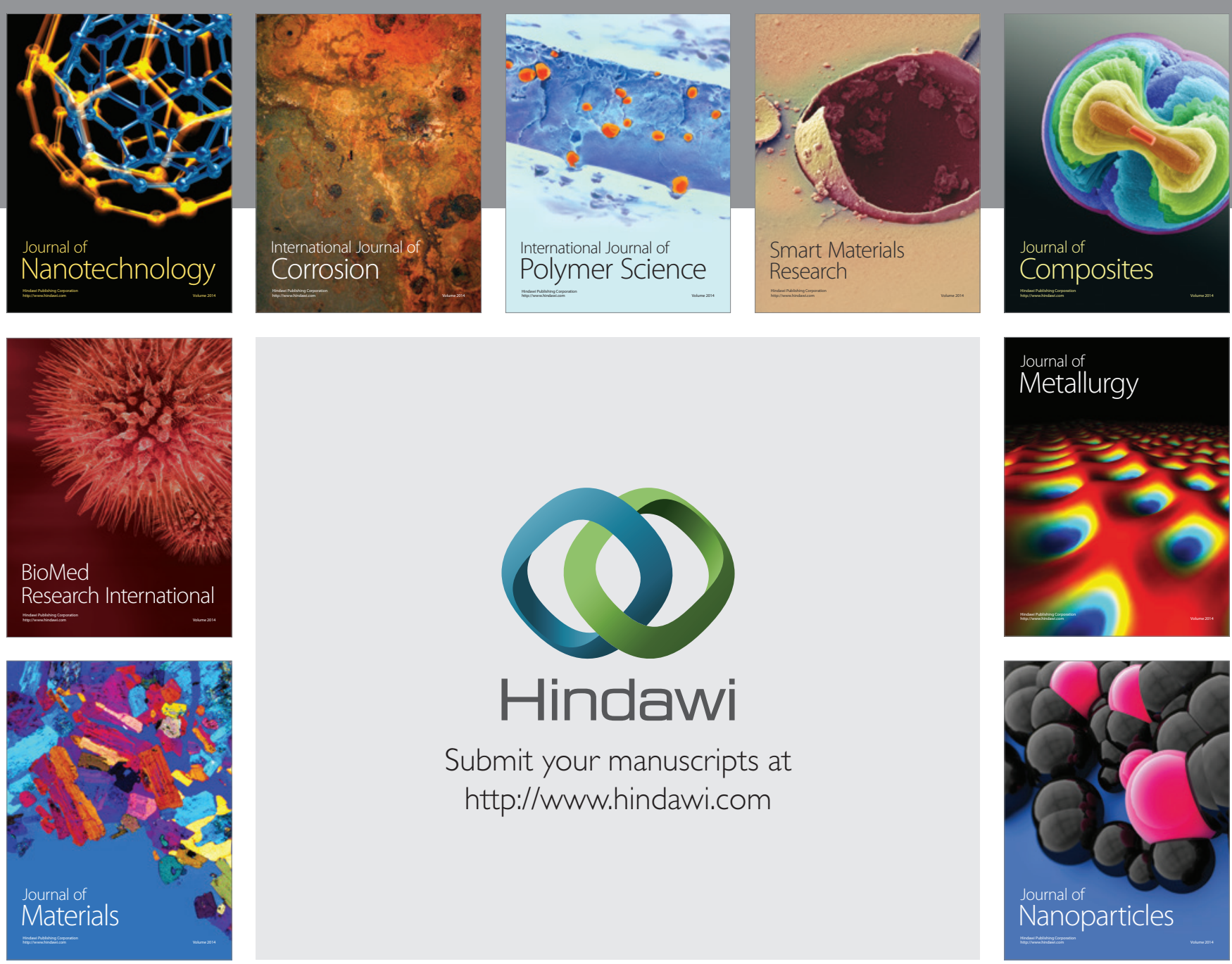

Submit your manuscripts at http://www.hindawi.com
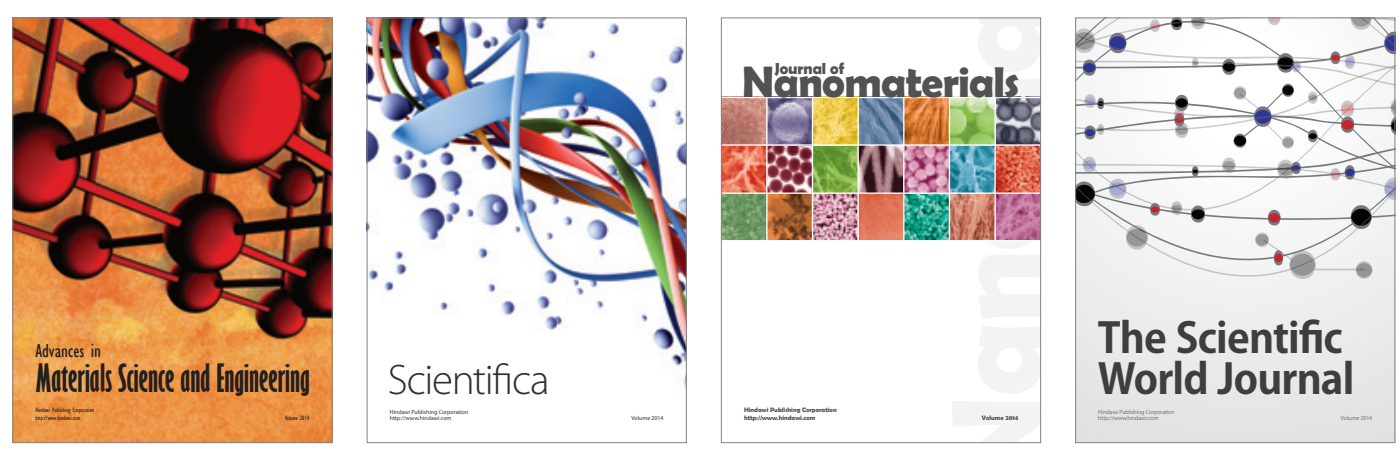

\section{The Scientific World Journal}
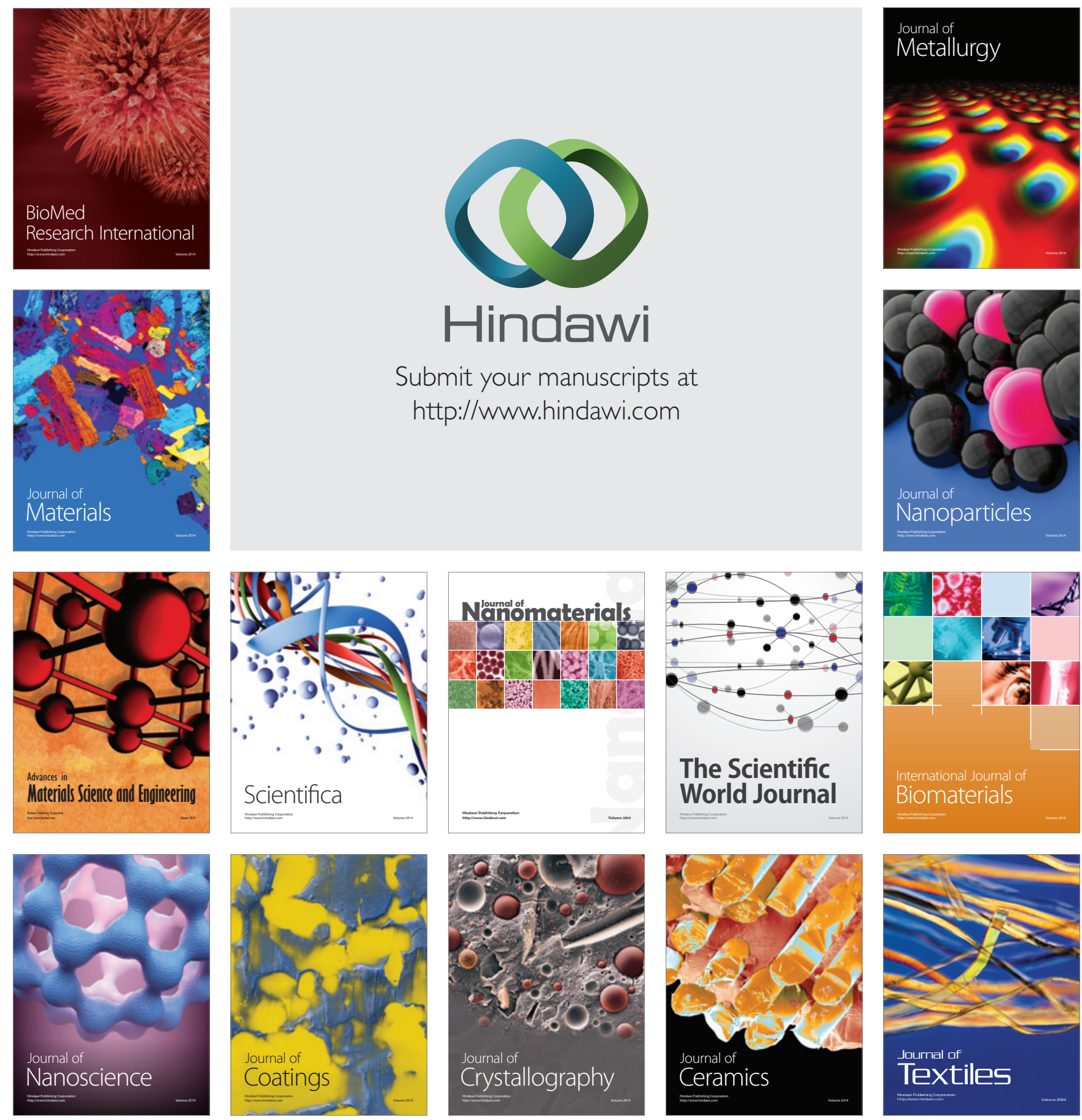